\title{
Limited orthodontic treatment in myotonic dystrophy II
}

\author{
Aurelia Magdalena Enache, Alexandru Marghescu, Roxana Antoanela Baluta, \\ Maria Otilia Blajin, Maria Cristina Pomana \\ Department of Orthodontics and Dentofacial Orthopedics, Faculty of Dental Medicine, \\ "Carol Davila" University of Medicine and Pharmacy, Bucharest, Romania
}

\begin{abstract}
Rationale. Myotonic dystrophy (MD) is a multisystemic autosomal dominant disease characterized by myotonia and progressive muscular weakness and atrophy.

Objective. The purpose of this study was to describe the dental, skeletal and muscular features in a family with myotonic dystrophy type II and to discuss possible therapeutic strategies.

Methods and results. This study presents the case of a family (a mother and two daughters) diagnosed with myotonic dystrophy type II. Beside the medical history and genetic tests, each subject underwent a clinical examination including impression taking, intra- and extraoral photographs and cephalometric analysis. Our investigations revealed alterations in the transversal and vertical planes.

Conclusions. Our findings were consistent with previously reported craniofacial features of patients affected by myotonic disorders, and they may be important diagnostic signs of a congenital muscular disease. We found that the most predominant malocclusions were the anterior open bite and posterior cross bite, but the tendency to class III malocclusion is in contradiction with theirfindings.
\end{abstract}

Keywords: myotonic dystrophy type II, long face syndrome, anterior open bite, limited orthodontic treatment

\begin{abstract}
Abbreviations:
MD - Myotonic dystrophy

RME - Rapid Maxillary Expansion

PDC - Palatally displaced canine
\end{abstract}

\section{INTRODUCTION}

Myotonic dystrophy (MD) is a multisystemic autosomal dominant disease caused by a defect localized to the long arm of chromosome 19, with an incidence of 1 in 20000 . (1,2). MD is characterized by myotonia and progressive muscular weakness and atrophy. It affects especially the muscles of the neck and face and the distal muscles of the limbs. The slow progression forms are usualy diagnosed in the second decade of life, and the early ones in the first 3 years of life. Early forms present a more severe symptomatic pattern that involve pulmonary and cardiac complications associated with mental deterioration, cataract, and a high risk of intraoperative malignant hyperthermia. MD patients have an increased oronasal resistance because of the alterations in the elastic properties of the pulmonary parenchyma (3).

Two young sisters, aged 14.7 years, M.S., and 10.6 years, A.S., came at Carol Davila University, Dental Medicine Faculty, Department of Orthodontics complaining of poor masticatory function and oral breathing. They were accompanied by their parents who wished to improve the life quality of their daughters, being aware of the impact of their 
general condition. Their medical history of MD makes the outcome of the orthodontic treatment unpredictable and difficult to control.

\section{MATERIALS AND METHODS}

The purpose of this article was to describe the skeletal, dental and muscular features in a family with MD and limitations of the orthodontic treatment.

General medical pathology of the mother revealed that she was diagnosed with myotonic dystrophy type II, after she gave birth of her first child. She received no orthodontic treatment (as she never attended a specialist), even though her masticatory function worsened over the time.

Beside the medical history and genetic tests, each subject underwent a clinical examination including impression taking, intra- and extraoral photographs and cephalometric analysis. We used Dolphin Imaging v11.5 to perform the Hasund analysis on all three cephalograms. The parameters considered for the study were as follows: antero-posterior parameters (SNA angle, SNB angle, ANB angle, Wits index) and vertical parameters (NS/ML, ML/ NL, and N-SP'/SP'-Gn).

\section{RESULTS}

A.S. and M.S. were diagnosed in the second year of life with MD, when were noted their delay and difficulties of doing normal activities up to their age. They were able to use their feet for standing, for the first time at 1.6 years old, and started walking after they were 2 years old. More than that,
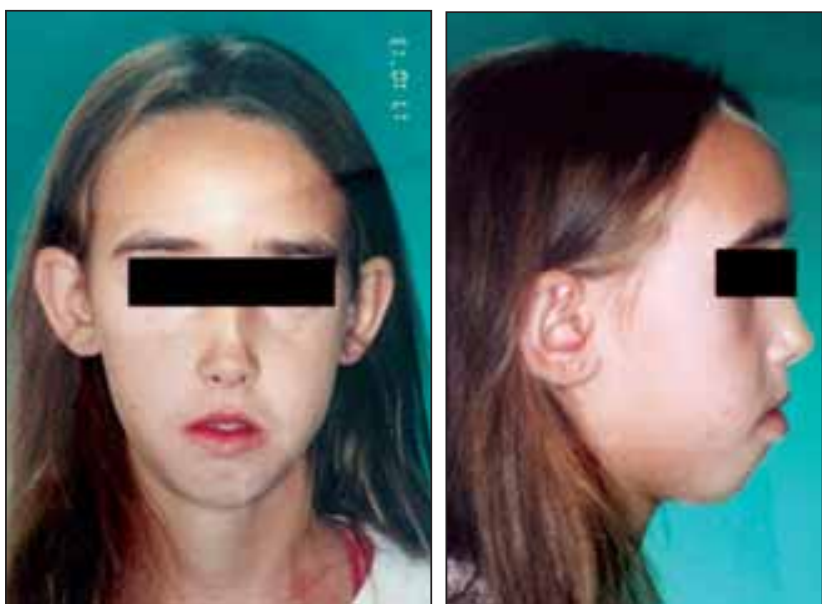

FIGURE 1. Extraoral photographs (front and profile) of A.S. activities like walking, climbing stairs and eating need permanent supervision from their parents, because of their inability to do them properly.

Myotonic dystrophy impairs the normal function of the masticatory muscles leading to vertical alteration in the craniofacial growth.

A.S. had a severe long face pattern, a convex facial profile due to clockwise mandible rotation and midface deficiency. Mentalis muscle strain compensates lip incompetence.There is also facial asymmetry due to uneven development of the two hemifaces at mandibular angle.
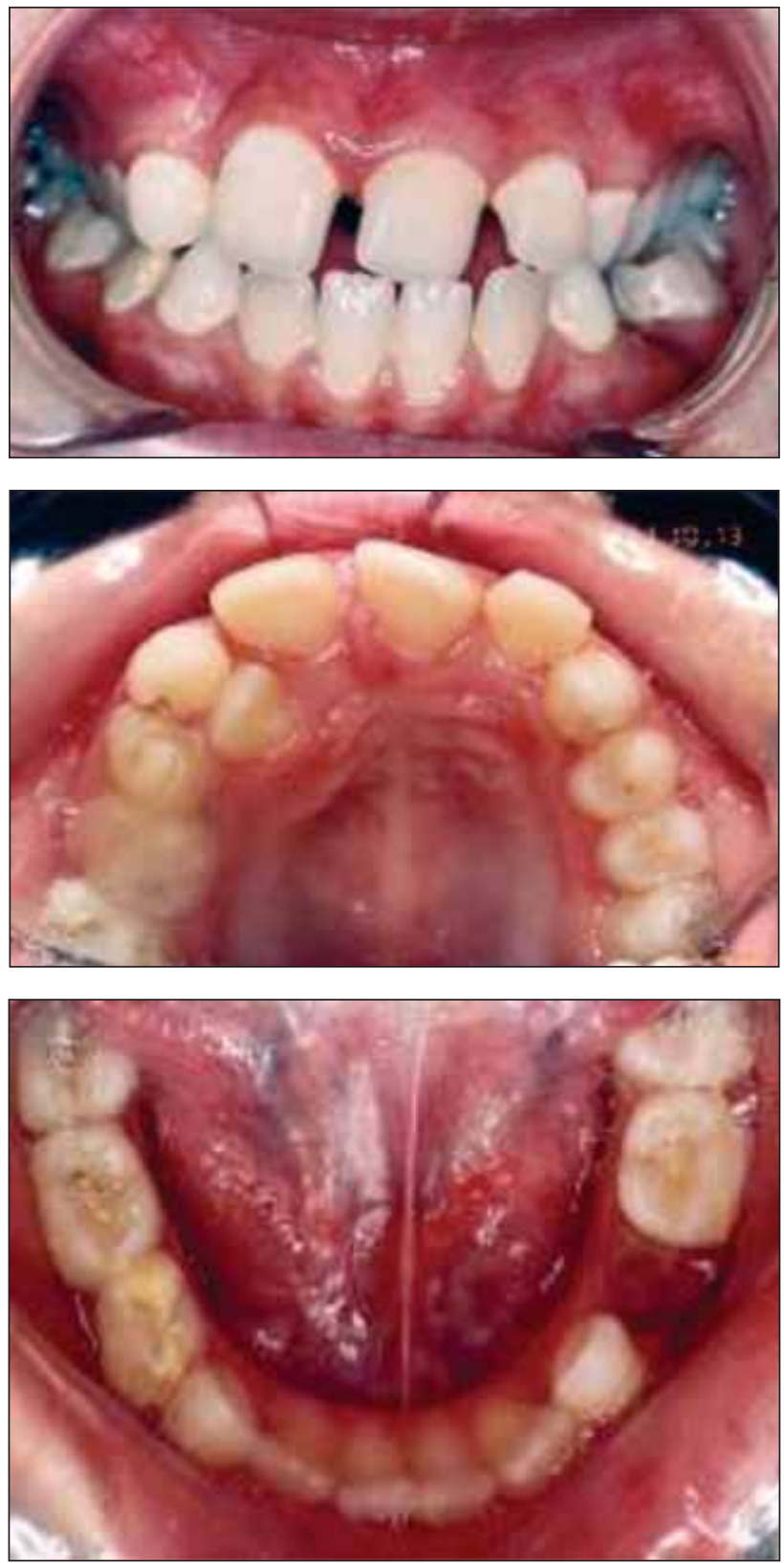

FIGURE 2. Patient A.S. intraoral photographs

The intraoral examination revealed a mixed dentition with chaotic dental eruption, due to car- 
ies. She presented maxillary flared incisors with spacing, except upper right lateral incisor, which was palatally blocked. She showed bilateral crossbite, severe space discrepancy for all teeth to be erupting, more remarkable in the the upper right side, where there was an important lack of space for canine to erupt. The patient showed a narrow maxillary arch, midline diastema and midline was off center to the right.

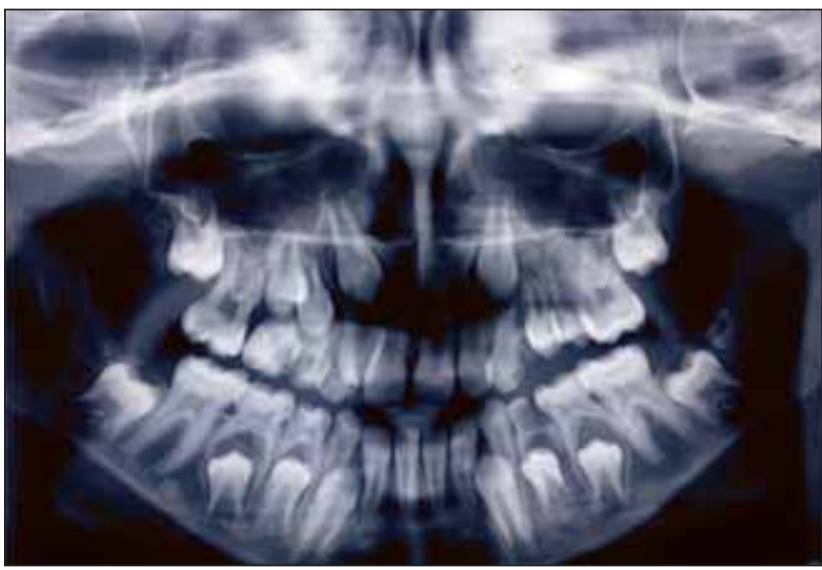

FIGURE 3. Panoramic X-ray of A.S.

Upper right canine was tilt and mesially, positioned intraosseous (PDC) with high risk of being impacted and to produce root resorption of upper right lateral incisor.

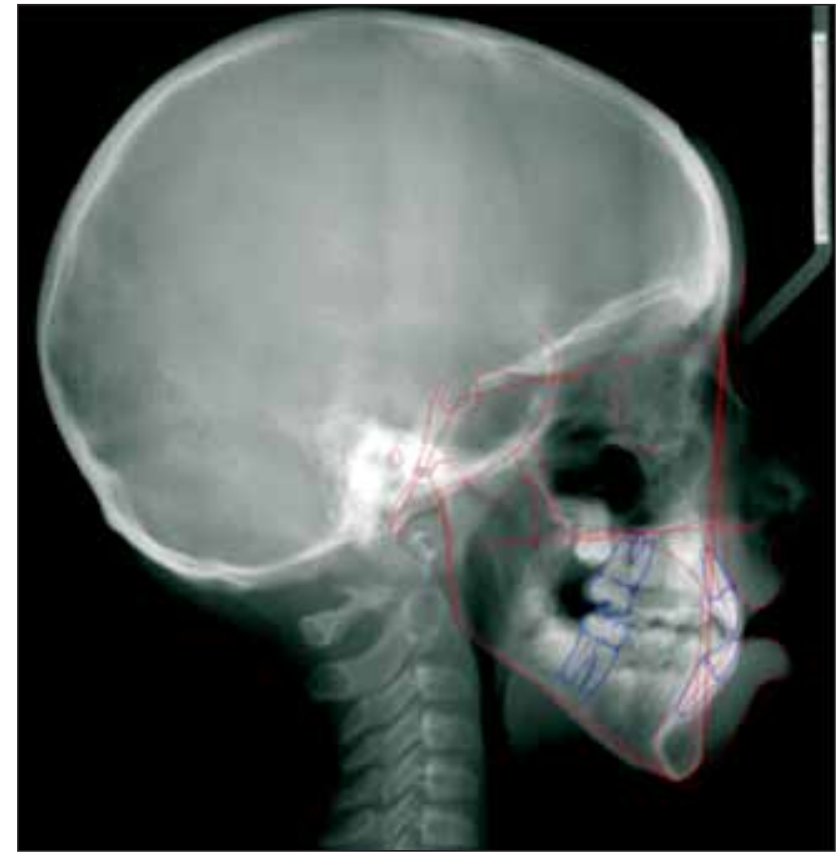

FIGURE 4. Cephalometric X-ray of A.S.

The cephalometric analysis showed increased craniomandibular (NS/ML), mandibular-palatal planes (ML/NL) and gonial angles and a long lower anterior face height ( $\left.\mathrm{Sp}{ }^{\prime}-\mathrm{Gn}=59.1 \mathrm{~mm}\right)$. Also, it was noticed biretrusive $\left(\mathrm{SNA}=76.9^{\circ}, \mathrm{SNB}=73.7^{\circ}\right)$ and long face pattern $\left(\mathrm{ML}-\mathrm{NL}=37.6^{\circ}\right)$, midface deficiency, mandibular incisors seemed to be tilted

\section{Group/Measurement}

SNA $\left({ }^{\circ}\right)$
SNB $\left({ }^{\circ}\right)$
ANB $\left({ }^{\circ}\right)$

Facial Plane to SN (SN-NPog) $\left({ }^{\circ}\right)$

SN - Basion $\left({ }^{\circ}\right)$

H-Angle ( $\mathrm{Pg}$ ' $\left.\mathrm{OL}-\mathrm{Pg} \mathrm{Na}^{\prime}\right)\left(^{\circ}\right)$

ML/NL ( $\left.{ }^{\circ}\right)$

$\mathrm{NL} / \mathrm{NSL}\left({ }^{\circ}\right)$

Ar-Go-Gn $\left({ }^{\circ}\right)$

$\mathrm{MP}-\operatorname{SN}\left({ }^{\circ}\right)$

Interincisal Angle (01-L1) $\left({ }^{\circ}\right)$

O1 - NA (mm)

U1 - NA $\left(^{\circ}\right)$

L1 - NB $\left(^{\circ}\right)$

L1 - NB (mm)

Pog - NB (mm)

Nasion - Sp' (mm)

Gnathion - Sp' (mm)

$N$ - Sp' / Sp' - Gn (\$)
Value Norm Std Dev Dev Norm

\begin{tabular}{|c|c|c|c|c|c|}
\hline 76.9 & 82.0 & 3.5 & 70 & & 90 \\
\hline 73.7 & 80.0 & 3.0 & 20 & D & 90 \\
\hline 3.1 & 2.0 & 2.4 & $-10 \quad-5$ & & 10 \\
\hline 73.8 & 80.0 & 3.5 & 70 & & 90 \\
\hline 131.6 & 131.0 & 4.5 & 110,120 & & 140,150 \\
\hline 18.2 & 10.0 & 4.0 & $-10, ?$ & 15 & 20 \\
\hline 37.6 & 20.0 & 3.0 & 10 & $\$$ & \\
\hline 11.8 & 8.0 & 3.0 & 9 & 10 & -20 \\
\hline 146.4 & 122.0 & 5.0 & 100,110 & & 190,148 \\
\hline 49.4 & 29.0 & 5.0 & 10.20 & & $5 e^{\prime}$ \\
\hline 124.1 & 130.0 & 5.0 & 110,120 & & 290,150 \\
\hline 2.2 & 4.0 & 1.0 & 2. & & e \\
\hline 18.1 & 22.0 & 4.0 & 10 & & 40 \\
\hline 34.7 & 24.0 & 2.0 & 15 & & -90 \\
\hline 6.7 & 4.0 & 1.0 & 3 & & 7 \\
\hline 0.1 & $\mathrm{~N} / \mathrm{A}$ & $\mathrm{N} / \mathrm{A}$ & & & \\
\hline 44.8 & 55.4 & 3.0 & & & 20 \\
\hline 59.1 & 69.6 & 4.9 & 50 & 6 & 30 \\
\hline 75.9 & 79.7 & 5.6 & 60 & p & 90,190 \\
\hline
\end{tabular}

FIGURE 5. Hasund cephalometric analysis of A.S. 
buccally, due to downward and backward rotation of mandible, interincisal angle $124.1^{\circ}$.
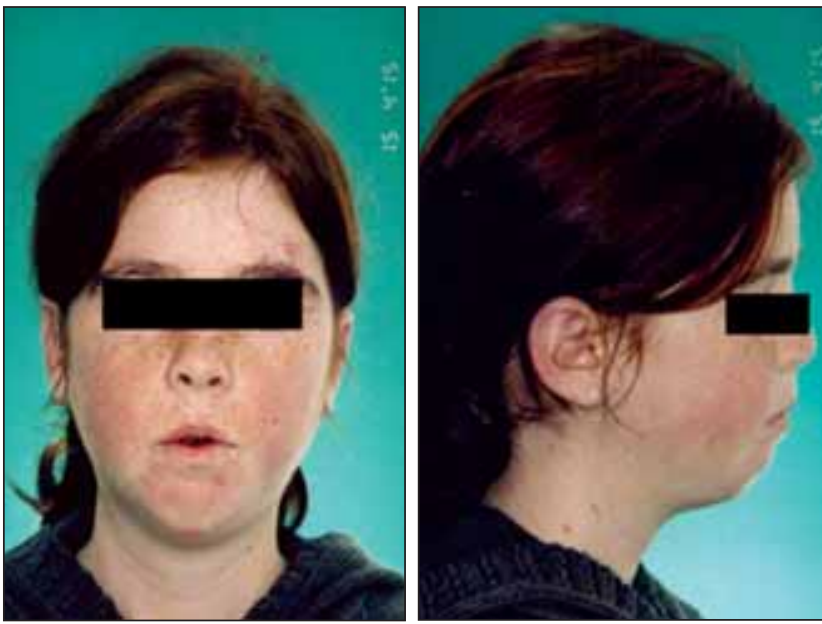

FIGURE 6. Extraoral photographs (front and profile) of M.S.
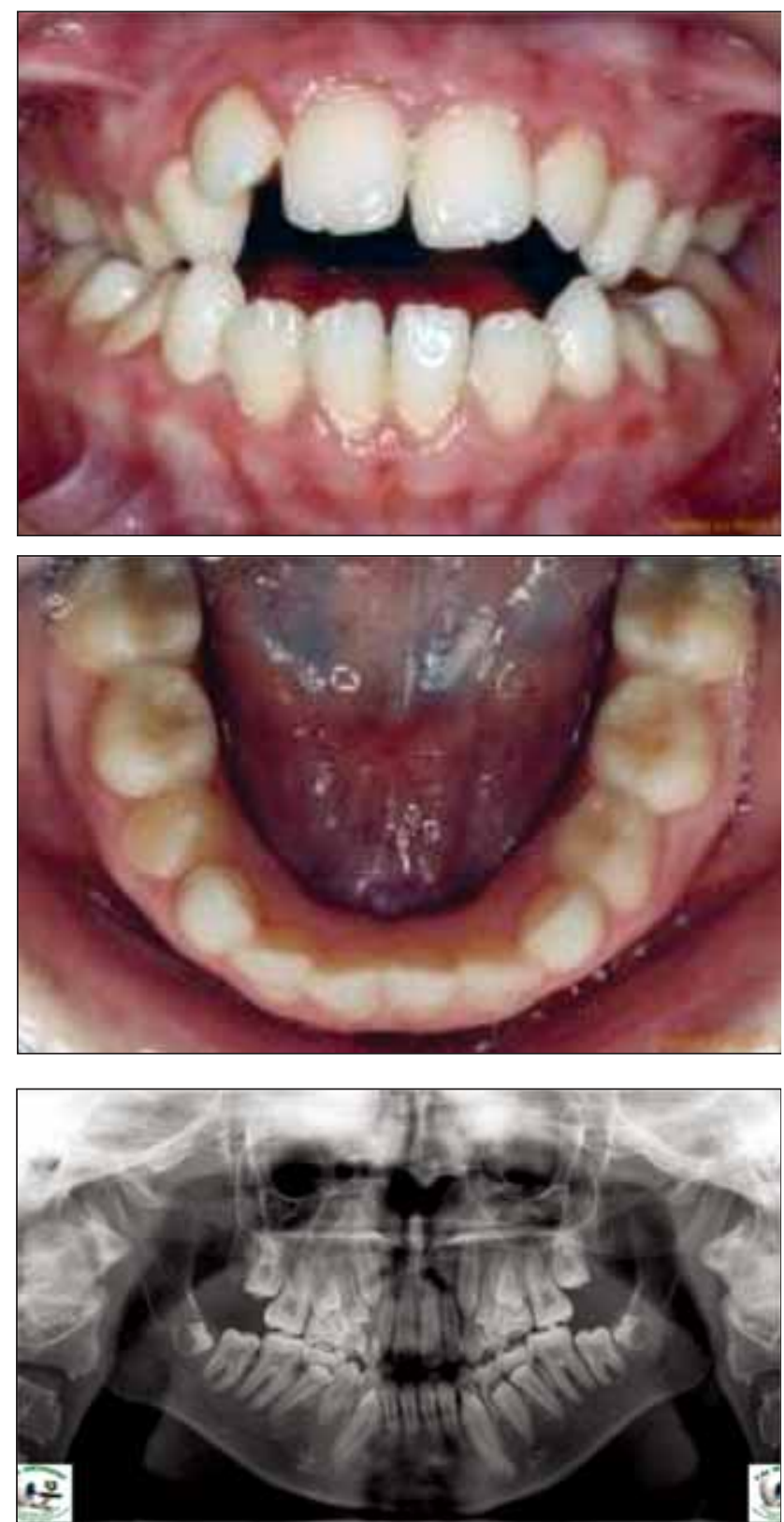

M.S. presented facial asymmetry with long face pattern, lip incompetence, dropping lower lip and a midface deficiency. She had a convex facial profile due to downward and backward mandible rotation and a flattened mentolabial fold due to mentalis muscle strain in an effort to balance labial incompetence.

The intraoral examination revealed a mixed dentition, maxillary incisors proclination, lack of space with a narrow maxillary arch, bilateral crossbite and severe anterior open bite with a right lateral incisor maximum of $7 \mathrm{~mm}$.

The panoramic X-ray revealed mesial inclination of all intraosseous teeth. Patient presented displacement of the upper right canine (on the same side as her sister) which may suggest a genetic inheritance aspect.

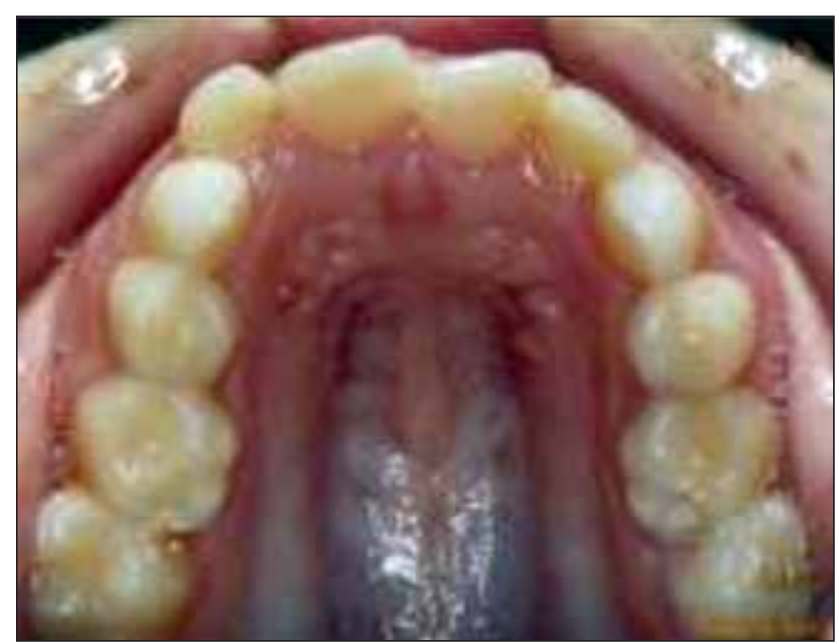

FIGURE 7. Patient M.S. intraoral photographs

FIGURE 8. Panoramic X-ray of M.S. 


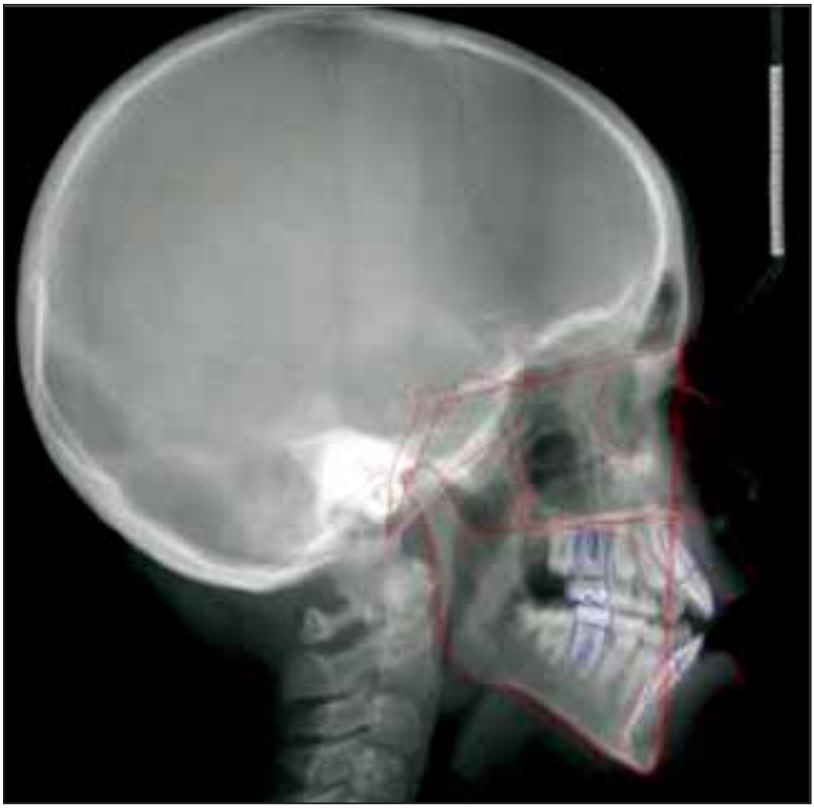

FIGURE 9. Cephalometric X-ray of M.S.

The cephalometric examinations showed increased craniomandibular (NS/ML), mandibular-palatal planes $\left(\mathrm{ML} / \mathrm{NL}=35.2^{\circ}\right)$ and gonial angles and long lower anterior face height (Sp'-Gn=66.9 mm). Also were noticed biretrusive $\left(\mathrm{SNA}=78^{\circ}, \mathrm{SNB}=73.6^{\circ}\right)$ and long face pattern (ML$\mathrm{NL}=35.2^{\circ}, \mathrm{NL}-\mathrm{NSL}=12^{\circ}$ ), proclined incisors, interincisal angle of $116.6^{\circ}$ and preangular notch, due to bone plasticity and clockwise mandible rotation.

Patients' mother, V.S.S. ( aged 34 and 8 months), having same disease, presented the same facial fea-

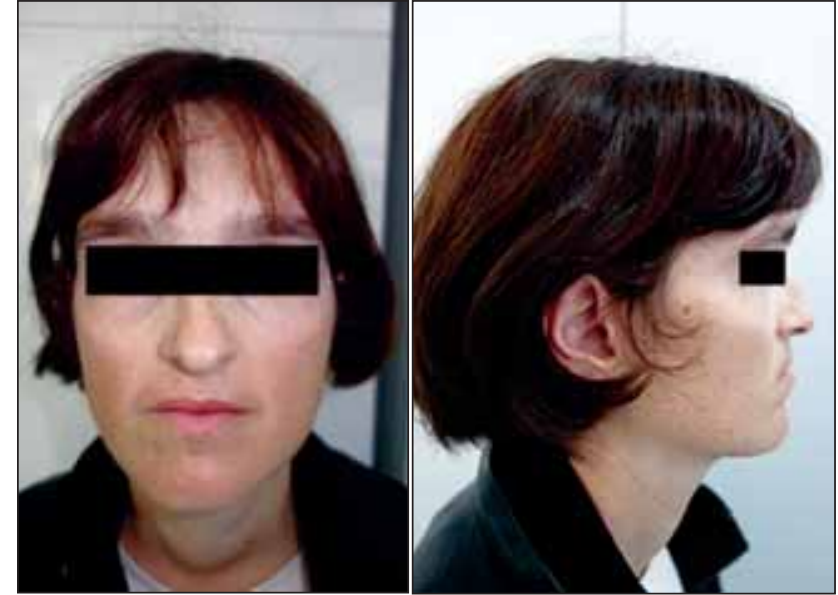

FIGURE 11. Extraoral photographs (front and profile) of the mother (V.S.)

tures, but less obvious, compared to the girls. She had facial asymmetry, with straight profile, long face, lip competence and mild clockwise mandible rotation. The facial asymmetry to the right was noticed in all three family members, suggesting an hereditary aspect.

The intraoral examination revealed a permanent dentition, abrasion of the teeth in both arches, more severe in the incisal area and a high susceptibility to caries and periodontal disease. She exhibited severe crowding in the mandibular anterior area with left canine lingually positioned, a narrow maxillary arch and anterior crossbite.

Hassund analysis revealed a retrognathic class III skeletal pattern with an ANB of -2.2, a SNA of

\section{Group/Measurement}

SWA $\left({ }^{\circ}\right)$

SNB $\left({ }^{\circ}\right)$

ANB $\left({ }^{\circ}\right)$

Facial Plane to SN (SN-NPog) $\left({ }^{\circ}\right)$

SN - Basion $\left({ }^{\circ}\right)$

H-Angle (Pg'OL-Pg'Na') ( $\left.{ }^{\circ}\right)$

$\mathrm{ML} / \mathrm{NL}\left({ }^{\circ}\right)$

NL/NSL $\left({ }^{\circ}\right)$

Ar-Go-Gn $\left({ }^{\circ}\right)$

MP - SN $\left(^{\circ}\right)$

Interincisal Angle (01-L1) $\left({ }^{\circ}\right)$

01 - NA $(\mathrm{mm})$

$\mathrm{O} 1$ - NA $\left({ }^{\circ}\right)$

L1 - NB $\left({ }^{\circ}\right)$

$\mathrm{L} 1$ - NB (min)

Pog - NB (mm)

Nasion - Sp' (min)

Gnathion - Sp' (mm)

$N$ - Sp' / Sp' - Gn (t)
Value Norm Std Dev Dev Norm

$\begin{array}{rrr}78.0 & 82.0 & 3.5 \\ 73.6 & 80.0 & 3.0 \\ 4.4 & 2.0 & 2.4 \\ 73.7 & 80.0 & 3.5 \\ 125.7 & 131.0 & 4.5 \\ 16.4 & 10.0 & 4.0 \\ 35.2 & 20.0 & 3.0 \\ 12.0 & 8.0 & 3.0 \\ 145.4 & 122.0 & 5.0 \\ 47.2 & 29.0 & 5.0 \\ 116.6 & 130.0 & 5.0 \\ 5.4 & 4.0 & 1.0 \\ 25.7 & 22.0 & 4.0 \\ 33.3 & 24.0 & 2.0 \\ 8.3 & 4.0 & 1.0 \\ 0.1 & \mathrm{~N} / \mathrm{A} & \mathrm{N} / \mathrm{A} \\ 45.9 & 55.4 & 3.0 \\ 66.9 & 69.6 & 4.9 \\ 68.6 & 79.7 & 5.6\end{array}$

FIGURE 10. Hasund cephalometric analysis of M.S. 

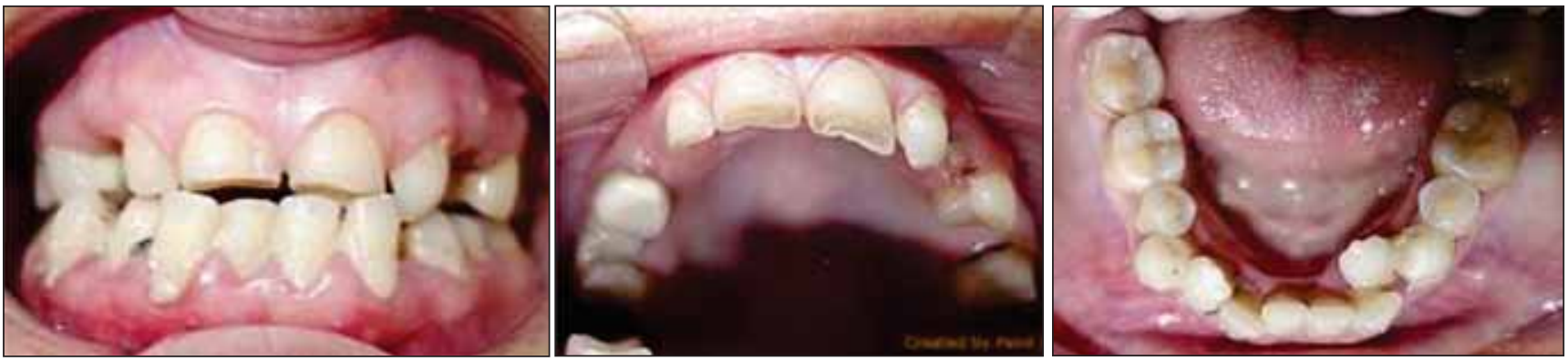

FIGURA 12. Patient V.S. intraoral photographs

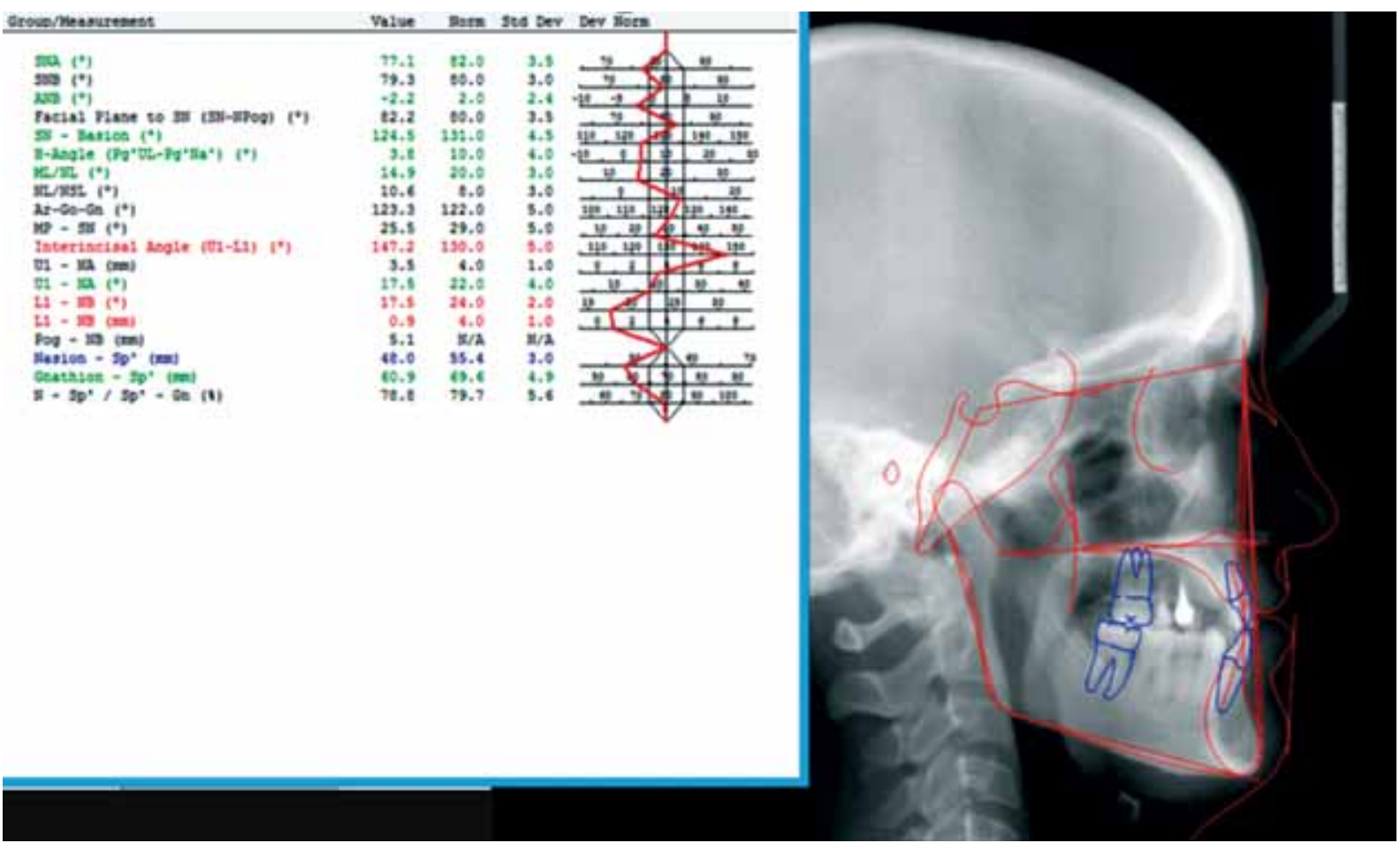

FIGURE 13. Hasund cephalometric analysis of the mother

$77.1^{\circ}$ and SNB of $79.3^{\circ}$, AoBo of -2.5 and a high angle facial type $\left(\mathrm{ML} / \mathrm{NL}=14.9^{\circ}, \mathrm{MP}-\mathrm{SN}=25.5^{\circ}\right.$, $\mathrm{N}-\mathrm{SP}$ '/SP'-Gn= $78.8^{\circ}$ ).

The extraoral examination revealed similar aspects of the facial appearance related to the weakness of the muscles in the face and the jaws. All three family members had myopathic facies (4): expressionless face with sunken cheeks, bilateral ptosis. They appeared to have a thin, 'swan neck' and modified head posture. With 'long face' syndrome, narrow bizygomatic face width, they had a convex profile, labial incompetence and a dropping lower lip.

The intraoral examination revealed a large tongue in abnormal position at rest and tongue movement impairment, poor oral hygiene with multiple cavities and periodontal disease.
All patients had high angle vertical pattern, that can worsen over time, because of the muscular atrophy progression.

\section{TREATMENT PLAN}

The treatment objectives were: maxillary transversal expansion, establish a proper overjet and overbite, eliminate crowding, establish harmonious functional occlusion, improve the masticatory function and muscular rehabilitation.

The ideal treatment was represented by orthognatic surgical treatment associated with orthodontic treatment. For these particular patients, the general anesthesia had a potential risk for malignant hypertemia. As a result, the treatment was focussed on improving the masticatory function. 
For both patients, the treatment consisted of the transverse expansion of the maxilla using a RME (Rapid Maxillary Expansion) appliance, with a Hyrax screw soldered to orthodontic bands on the permanent first molars for A.S. and on bite-blocks for M.S. The RME appliance was left in place as a retention appliance for 6 months, to allow new bone formation at the maxillary median suture.

In the case of A.S. was used a facial mask (FM) for sagittal lengthening and a removable apliance for the distalization of upper right first molar, to create space for the right second upper bicuspid . After this period, the orthodontic treatment with conventional fixed appliance was initiated and was still ongoing, with visible improvement of facial esthetics.

For the other patient, M.S., the treatment progression was not favourable.

\section{DISCUSSIONS}

There is not much literature about MD and its dental and facial characteristics. Taking into consideration that facial appearance has an important impact on the personal, professional and social life, and that the orthodontic treatment can improve the facial appearance, the study of this kind of disease, which affect the facial appearance and normal growth of the craniofacial structures can help early diagnosis and the appropriate orthodontic treatment.

This article supports most of the existing results, obtained in other studies, regarding myotonic dystrophy type II, having its limits of being a case report.

The high prevalence of impaired facial expression found in this study was in accordance with other studies on younger population with $\operatorname{MD}(5,6)$. We noticed similar facial features as those described by Nadaj (6)- long face, hypomimia, masseter muscles weakness, atrophy and myotonia, large tongue in abnormal position at rest, and tongue movements impairment due to myotonia, mouth breathing and gothic palate. Similar to D.Nadaj (6), our patients suffered from mastication difficulties, insufficient oral hygiene with multiple cavities and periodontal disease, and required multidisciplinary care.
Our findings were consistent with previously reported craniofacial features of patients affected by myotonic disorders, and they might be important diagnostic signs of a congenital muscular disease. We also found that the most predominant malocclusions were the anterior open bite and posterior crossbite, similar to Kiliaridis and Katsaros (7), but the tendency to class III malocclusion was in contradiction with their findings.

Even though earlier studies reported a high frequency of increased overjet in patients with MD, we did not encounter this in our subjects $(7,8)$.

The results of this case report showed a reduced maxillary and mandibular length, in accordance with Luiz Alves Oliveira-Neto (5), but different from their findings, the anteriorposterior position of the maxilla (SNA) and the mandible (SNB) were not in the normal range. For our patients SNA and SNB values were decreased. These findings could be correlated with the results of the study on Romanian population, which stated that mean value of SNA angle is less than normal mean value. (9)

Similar to Barreto $(10,11)$, our patients presented a reduced muscular mass which can determine increased mandibular angle.

In terms of the treatment, it could be shown that this disease needed multidisciplinary care, including not only dentistry, but also general medicine.

In our cases, we noticed a limited improvement of the function and the aesthetics, after the orthodontic treatment.

A high success rate of the orthodontic treatment alone, with reducing the need for the orthognatic surgery depends on an early diagnosis, before the facial bones had full developed.

\section{CONCLUSIONS}

Early diagnosis of MD is essential in order to start the treatment as soon as possible. The treatment is multidisciplinary, involving specialists in the fields of orthodontics and surgery, anesthesiologists and neurologists.

Particularity for these cases is the limitation of surgery because of the potential risk of malignant hyperthermia. So, an early orthodontic treatment can reduce the need for orthognatic surgery, improving the appearance and functionality of the patient. 


\section{REFERENCES}

1. Bouhour F., Bost M., Vial C. Steinert disease. 2007 Jun; 36(6 Pt 2):965-71. Epub $2007 \mathrm{Feb}$

2. Friedman R.D., Joe J., Bodak L.Z. Myothonic dystrophy: report of a case. Oral Surg Oral Med Oral Pathol 1980;5:229-32.

3. Fodil R., Lofaso F., Annane D., Falaise L., Lejaille M., Raphael J.C., Isabey D., Louis B. Upper airway calibre and impedance in patients with Steinert's myotonic dystrophy. Respir Physiol Neurobiol 2004 Nov 30;144(1):99-1074.

4. Hellmuth Muller, Johanna A., Punt-Van Manen. Maxillofacial deformitis in patient with dystrophia myothonica and anaesthetic implications. Max Fac Surg 1982; 10:224-228.

5. Luiz Alves Oliveira-Neto a, Mariade Fátima B. Melo, Alexandre A. Franco, Alaíde H.A. Oliveira, Anita H.O. Souza, Eugênia H. O. Valença, Isabela M.P.A. Britto, Roberto Salvatori, Manuel H. Aguiar-Oliveira. Cephalometric features in isolated growth hormone deficiency

6. D. Nadaj, A. Lusakowska, D. Maciejak, A.M. Kaminska, M. Zadurska. Dental and orthodontic aspects of myotonic dystrophy type 1

7. Kiliaridis S., Katsaros C. The effects of myotonic dystrophy and Duchenne muscular dystrophy on the orofacial muscles and dentofacial morphology. Acta Odontol Scand 1998; 56:369-374.

8. Kiliaridis S., Mejersjo C., Thilander B. Muscle function and craniofacial morphology: a clinical study in patients with myotonic dystrophy. Eur J Orthod 1989; II:131-138.

9. Lidia Boboc, Dragos Stanciu, Magdalena Enache - Repartition des schemas faciaux chez une population orthodontique d'adolescents roumains. Les Journees de l'Orthodontie, Paris, nov. 2000.

10. Barreto-Filho, J.A.S., M.R.S. Alcântara, R. Salvatori et al. Familial isolated growth hormone deficiency is associated with increased systolic blood pressure, central obesity and dyslipidemia. J Clin Endocrinol Metab 2002. 87:2018-2023.

11. de Barretto, E.S.A., M.S.Gill, M.E.S. Freitas, M.M.G. Magalhaes, A. H.O. Souza, M.H. Aguiar-Oliveira, P.E. Clayton. Serum leptin and body composition in children with familial GH deficiency (GHD) due to a mutation in the growth hormone-releasing hormone (GHRH) receptor. Clin Endocrinol (Oxf) 1999. 51:559-564. 